\title{
Glass and glass-ceramics along the $\mathrm{SrTiO}_{3}-\mathrm{NaPO}_{3}$ line
}

\author{
H. Sinouh ${ }^{1,2}$, L. Bih ${ }^{1, a}$, A. El Bouari ${ }^{2}$, T. Baudin ${ }^{3}$, P. Berthet ${ }^{3}$, R. Haumont ${ }^{3}$ \\ and D. Solas ${ }^{3}$ \\ ${ }^{1}$ Laboratoire de Physico-Chimie des Matériaux LPCM, Faculté des Sciences et Techniques Errachidia \\ 2 Laboratoire de Physico-Chimie des Matériaux Appliqués, Faculté des Sciences Ben M'Sik Casablanca \\ 3 Laboratoire de Physico-Chimie de l'État Solide, Bâtiment 410, Institut de Chimie Moléculaire et Matériaux \\ d'Orsay, UMR CNRS 8182, Université Paris-Sud 11, 91405 Orsay Cedex, France
}

\begin{abstract}
The $\mathrm{xSrTiO}_{3}-(1-\mathrm{x}) \mathrm{NaPO}_{3}(\mathrm{x}=0-0.20 \mathrm{~mol} \%)$ glasses were prepared by the conventional melt-quenching method. The amorphous state of the samples was verified by X-ray diffraction. The glass-ceramic materials were obtained by the well known thermal controlled crystallization process. It is found that several physical properties such as the density, molar volume, and the glass transition temperature depend strongly on the chemical composition. Vickers test on the glasses showed that the micro-hardness increases with the $\mathrm{SrTiO}_{3}$ content. The structural approach of the glasses was realized by IR spectroscopy. This technique has highlighted the co-existence of different phosphate and titanium structural units in the glassy-matrix. Crystallization of the glasses was enhanced by heat treatments and followed by X-ray diffraction. A mechanism for this glass crystallization was proposed.
\end{abstract}

\section{INTRODUCTION}

Phosphate glasses are used in various applications such as bone transplantation, glass to metal seals, confining radioactive wastes, fast ion conductors, laser host materials, etc. . . [1].

Strontium titanate $\mathrm{SrTiO}_{3}$ is considered a promising material for tunable microwave applications due to its high dielectric constant, high dependence of dielectric constant on the applied field, and low losses [2].

In the present work, our interest is focused on studying phosphate glasses inside the $\mathrm{NaPO}_{3}-\mathrm{SrTiO}_{3}$ system for the first time. The experimental requirements for the synthesis were determined and the characterization by density measurements, thermal analysis, Vickers test and infrared spectroscopy were realized.

\section{EXPERIMENTAL PROCEDURES}

The $(1-\mathrm{x}) \mathrm{NaPO}_{3}-\mathrm{xSrTiO}$ glasses with $0 \leq \mathrm{x} \leq 0.2 \mathrm{~mol} \%$ were prepared from appropriate contents of vitreous $\mathrm{NaPO}_{3}$ and $\mathrm{SrTiO}_{3}$ phase. The glasses were prepared by the conventional melt-quenching route. The amorphous state of samples was verified by X-ray diffraction using a Philips X'Pert apparatus equipped with a $\mathrm{CuK}_{\alpha} \mathrm{X}$-ray source and a Ni filter $\left(\lambda_{\mathrm{Cu}}=1.5406 \AA\right)$.

The crystallization process is realized by submitting the glass samples to heat treatments at $600^{\circ} \mathrm{C}$ in air for 3 hours.

The density measurements (D) of glasses are determined by the Archimedes method using diethyl orthophthalate as a fluid. Molar volume $\left(\mathrm{V}_{\mathrm{m}}\right)$ of each glass is derived from the density.

DTA runs were carried out for ground glass batches of about $50 \mathrm{mg}$ in nitrogen atmosphere at a heating rate of $10^{\circ} \mathrm{C} \mathrm{m^{-1 }}$ using a Perkin Elmer DTA-7 analyzer.

\footnotetext{
a e-mail: bihlahcen@yahoo.fr (L. Bih).
}

Vickers micro-hardness values were determined at room temperature in air using a Leitz instrument. Polished samples were subjected to a load of $100 \mathrm{~g}$ at an indentation time of $25 \mathrm{~s}$.

IR spectra of the glass-ceramics are carried out by means of $\mathrm{KBr}$ pellets in the frequency range 1400$400 \mathrm{~cm}^{-1}$ using a FTIR TENSOR27 spectrometer.

\section{RESULTS AND DISCUSSION}

\subsection{XRD analysis}

The width of the glassy region inside the system $\mathrm{NaPO}_{3}$ $\mathrm{SrTiO}_{3}$ was checked by X-ray diffraction analysis and the transparency of the samples. The homogeneous glasses could be elaborated up to $20 \mathrm{~mol} \%$ of $\mathrm{SrTiO}_{3}$. XRD patterns for different samples in the range of compositions $(0<\mathrm{x}<0.20)$ show only broad hallo around $25-35^{\circ}$ ( $2 \theta$ values) which confirm the glassy nature of these samples.

\subsection{Density and molar volume}

Results of the density measurements and the calculated molar volume of the studied glasses $\mathrm{xSrTiO}_{3}-(1-\mathrm{x}) \mathrm{NaPO}_{3}$ $(\mathrm{x}=0-0.20 \mathrm{~mol} \%)$ are represented at Fig.1 and gathered in Table 1. One can observe that the density and the molar volume increases and decreases, respectively, with the $\mathrm{SrTiO}_{3}$ content in the glass. The substitution of $\mathrm{NaPO}_{3}$ by $\mathrm{SrTiO}_{3}$ is accompanied with an increasing in molecular mass that's why probably the density variation shows the increasing trend with $\mathrm{SrTiO}_{3}$ content. A decrease of the molar volume versus composition parameter $(\mathrm{x})$ could not be interpreted in terms decreasing of the mean ionic radius related to the substitution of $\left(\mathrm{Na}^{+}+\mathrm{P}^{5+}\right)$ by $\left(\mathrm{Sr}^{2+}+\right.$ $\left.\mathrm{Ti}^{4+}\right)$ since $\mathrm{r}\left(\mathrm{Ti}^{4+}\right)=0.61 \AA, \mathrm{r}\left(\mathrm{Sr}^{2+}\right)=1.18 \AA, \mathrm{r}\left(\mathrm{Na}^{+}\right)=$ $1.02 \AA$ and $\mathrm{r}\left(\mathrm{P}^{5+}\right)=0.17 \AA[3]$. 


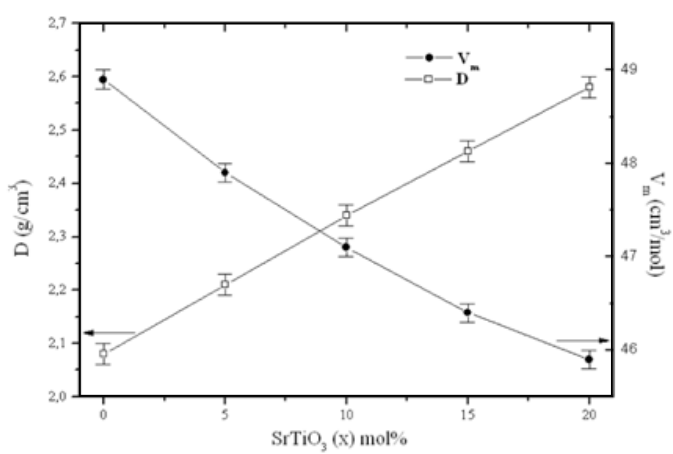

Figure 1. Density and molar volume as a function of composition (x) for the $\mathrm{xSrTiO}_{3}-(1-\mathrm{x}) \mathrm{NaPO}_{3}$ glass samples.

However, the observed decrease of the molar volume versus $\left(\mathrm{xSrTiO}_{3}\right)$ could be associated to the decreasing number of non-bridging oxygen atoms. In other words, this decrease is due to the decrease of bond length or interatomic spacing among the atoms of glass network which causes closing of the structure in agreement with the fact that when non-bridging oxygen (NBO) is converted to bridging oxygen $(\mathrm{BO})$ the average $\mathrm{M}-\mathrm{O}$ distance decreases [4-6]. Moreover, the variation $V=f(x)$ suggests the formation of more covalent $\mathrm{Sr}-\mathrm{O}$ and $\mathrm{Ti}-\mathrm{O}$ bonds with short lengths, instead of ionic $\mathrm{Na}-\mathrm{O}$ bonds, which reticules the phosphate network and lead to the close structure of the glasses [7].

Table 1. Some physical properties of the glasses.

\begin{tabular}{lcccc}
\hline $\mathrm{x}$ & $\begin{array}{c}\text { Density/ } \\
\mathrm{g} / \mathrm{cm}^{3}\end{array}$ & $\begin{array}{c}\text { Molar } \\
\text { Volume/ } \\
\mathrm{cm}^{3} / \mathrm{mol}\end{array}$ & $\begin{array}{c}\mathrm{Tg} / \\
{ }^{\circ} \mathrm{C}\end{array}$ & $\begin{array}{c}\mathrm{Hv} / \\
\mathrm{GPa}\end{array}$ \\
\hline 0 & 2.08 & 48.9 & 284 & 1.59 \\
0.05 & 2.21 & 47.9 & 393 & 1.76 \\
0.1 & 2.34 & 47.1 & 415 & 1.90 \\
0.15 & 2.46 & 46.4 & 430 & 2.07 \\
0.2 & 2.58 & 45.9 & 439 & 2.19 \\
\hline
\end{tabular}

\subsection{DTA analysis and Microhardness $\left(H_{v}\right)$}

Table 1 shows the value of the glass transition temperature $\left(\mathrm{T}_{\mathrm{g}}\right)$ of each glass. Figure 2 represents the variation of the glass transition temperature $\left(\mathrm{T}_{\mathrm{g}}\right)$ as a function of the $\mathrm{SrTiO}_{3}$ content. The substitution of $\mathrm{NaPO}_{3}$ for $\mathrm{SrTiO}_{3}$ leads to a large increase of $\mathrm{T}_{\mathrm{g}}$ in the glass and shows that the structure is strongly strengthened.

We assume that in this case, when strontium and titanium cations substitute sodium ions, -P-O... Sr and -P-O. . . Ti more covalent bonds are formed instead of ionic $\mathrm{Na}-\mathrm{O}$ links (the $\mathrm{Sr}$ and $\mathrm{Ti}$ electronegativities being larger than that of $\mathrm{Na}$ ). This means that the glasses will show high glass transition temperature [7].

Values of microhardness, $H_{v}$, for the glasses $\mathrm{xSrTiO}_{3}-$ $(1-\mathrm{x}) \mathrm{NaPO}_{3}$ are listed in Table 1 . It is seen that $H_{v}$ increases with the increase of titanium content. According to the chemical composition of the studied glasses, one can consider that P-O-P, P-O-Ti, Ti-O-Ti are the principal covalent bonds which determine the cohesive energies

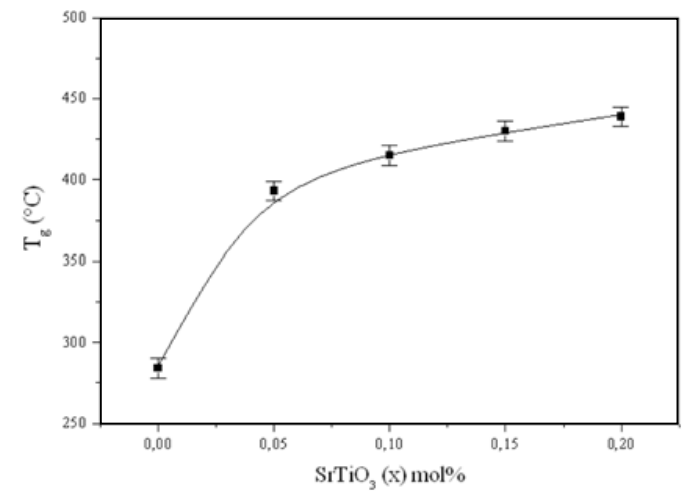

Figure 2. Glass transition temperature $\left(\mathrm{T}_{\mathrm{g}}\right)$ of the $\mathrm{xSrTiO}_{3}-$ $(1-\mathrm{x}) \mathrm{NaPO}_{3}$ glasses.

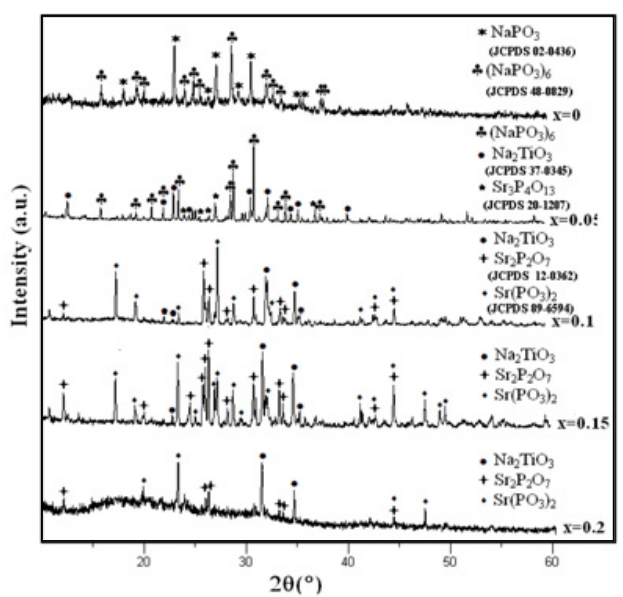

Figure 3. XRD patterns of the crystallized glasses inside the $\mathrm{xSrTiO}_{3}-(1-\mathrm{x}) \mathrm{NaPO}_{3}$ system.

of the network [8]. Therefore, the observed increase of $\mathrm{H}_{\mathrm{v}}$ with $\mathrm{SrTiO}_{3}$ could be explained by the formation of $\mathrm{P}-\mathrm{O}-\mathrm{Ti}$ and/or Ti-O-Ti linkages in their glassy-matrix.

\subsection{Crystallization of the glasses}

Figure 3 shows the obtained XRD patterns for the crystallized $\mathrm{xSrTiO}_{3}-(1-\mathrm{x}) \mathrm{NaPO}_{3}$ samples.

According to the composition it is observed that mainly metaphosphates and pyrophosphates, $\mathrm{Sr}_{3} \mathrm{P}_{4} \mathrm{O}_{13}$ and $\mathrm{Na}_{2} \mathrm{TiO}_{3}$ are the crystallized phases. When the glass composition contains large amount of $\mathrm{SrTiO}_{3}(\mathrm{x}=0.1$ and 0.2 ), the ratio of the perovskite $\mathrm{Na}_{2} \mathrm{TiO}_{3}$ phase increases and the $\mathrm{Sr}_{3} \mathrm{P}_{4} \mathrm{O}_{13}$ phase transforms to $\mathrm{Sr}_{2} \mathrm{P}_{2} \mathrm{O}_{7}$ and $\mathrm{Sr}\left(\mathrm{PO}_{3}\right)_{2}$ phases.

\subsection{IR spectra}

The IR spectra of the $\mathrm{xSrTiO}_{3}-(1-\mathrm{x}) \mathrm{NaPO}_{3}$ glasses are shown in Fig. 4.

The absorption bands of the given materials can be assigned as follows: (i) a band at $\left(1270 \mathrm{~cm}^{-1}\right)$ is due to the asymmetric stretch vibrations $(\mathrm{P}=\mathrm{O})[8]$ and the band lying in the range $1200-1170 \mathrm{~cm}^{-1}$ is related 


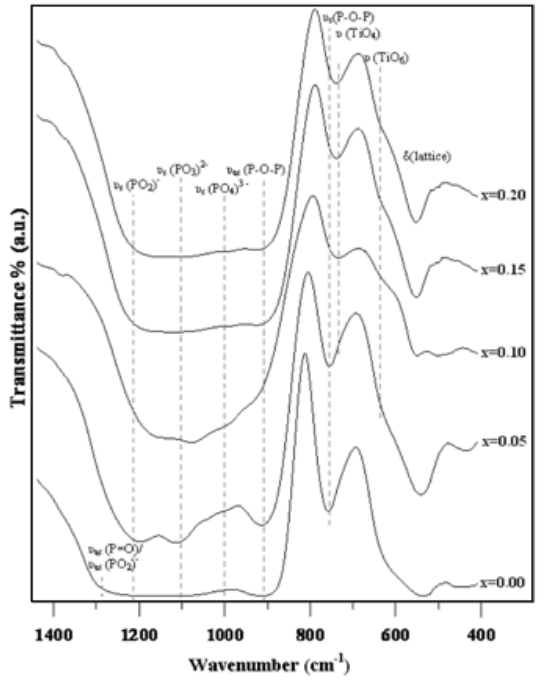

Figure 4. IR spectra of the $\mathrm{xSrTiO}_{3}-(1-\mathrm{x}) \mathrm{NaPO}_{3}$ glasses.

to the stretching vibration of the $\left(\mathrm{PO}_{2}\right)^{-}$group $[9,10]$, this band is intensity decreasing when $\mathrm{NaPO}_{3}$ content decreases; (ii) the intensity of the band at $\approx 750 \mathrm{~cm}^{-1}$, attributed to a stretching vibration of $\mathrm{P}-\mathrm{O}-\mathrm{P}$ bridges decreases with increasing $\mathrm{SrTiO}_{3}$ content $[9,10]$, but with further introduction of $\mathrm{SrTiO}_{3}$, this band is replaced by two new bands one at $735 \mathrm{~cm}^{-1}$ and another at $624 \mathrm{~cm}^{-1}$. These new bands are assigned respectively to $\mathrm{TiO}_{6}$ and $\mathrm{TiO}_{4}$ structural units [11,12]; (iii) the bands at 1070 and $1116 \mathrm{~cm}^{-1}$ present in all the spectra are assigned to high and low frequency components of the asymmetric stretch of the $\left(\mathrm{PO}_{3}\right)^{2-}$ terminal group, respectively [10]. The increase of $\mathrm{SrTiO}_{3}$ content induces the appearance of a broad band near $990-1038 \mathrm{~cm}^{-1}$ which is attributed to stretching vibration of $\mathrm{PO}_{4}$ [10]. The broad bands around $542 \mathrm{~cm}^{-1}$ and $430 \mathrm{~cm}^{-1}$ are associated with the bending vibrations of basic structural units of the network [8].

The significant bands detected in the region of $450-580,650-800,900-1270 \mathrm{~cm}^{-1}$ are attributed to metaphosphate $\left(\mathrm{PO}_{3}\right)^{-}$and pyrophosphate $\left(\mathrm{P}_{2} \mathrm{O}_{7}\right)^{4-}$ units [8] in accordance with functional groups of the crystalline phase identified by XRD: $\mathrm{NaPO}_{3}$ (JCPDS 02-0436), $\left(\mathrm{NaPO}_{3}\right)_{6}(\mathrm{JCPDS} 48-0829), \mathrm{Sr}\left(\mathrm{PO}_{3}\right)_{2}$ (JCPDS 89-6594) and $\mathrm{Sr}_{2} \mathrm{P}_{2} \mathrm{O}_{7}$ (JCPDS 12-0362).

\section{CONCLUSION}

The glasses inside the $\mathrm{xSrTiO}_{3}-(1-\mathrm{x}) \mathrm{NaPO}_{3}$ system were prepared by melt-quenching route and their physical properties (density, $\mathrm{Tg}, \mathrm{H}_{\mathrm{v}}$ ) increase with $\mathrm{SrTiO}_{3}$ ratio. IR spectra indicate the formation of different phosphate units along with $\mathrm{TiO}_{4}$ and $\mathrm{TiO}_{6}$ groups in the glasses. The crystallization of the glasses is performed by heat treatments and the obtained glass-ceramics contain sodium titanate $\mathrm{Na}_{2} \mathrm{TiO}_{3}$ (perovskite structure) phase rather than $\mathrm{SrTiO}_{3}$ phase.

The authors thank the VOLUBILIS Committee (MoroccoFrance) (project MA/09/206) for given financial support to this work.

\section{References}

[1] K.V. Shah, V. Sudarsan, M Goswami, A Sarkar, S Manikandan, Rakesh Kumar, B I Sharma, V K Shrikhande, G P Kothiyal, Bull. Mater. Sci. 26 (2003) 715-720.

[2] A.K. Tagantsev, V.O. Sherman, K.F. Astafiev, J. Venkatesh, N.J. Setter, J. Electroceram. 11 (2003) 5.

[3] Shannon R.D., Acta Crystallogr. A32 (1976) 751-67.

[4] Bih L., Nadiri A., Aride J. J Therm Anal Cal. 68 (2002) 965-72.

[5] Valente M.A., Bih L., Graça M.F.P. J Non Cryst Solids. 357 (2011) 55-61.

[6] Ganguli M., Rao K.J. J Non-Cryst Solids. 243 (1999) 51.

[7] A. Shaim, M. Et-tabirou, L. Montagne, G. Palavit. J Materials Research Bulletin. 37 (2002) 2459-2466.

[8] H. Sinouh, L. Bih, M. Azrour, A. El Bouari, S. Benmokhtar, B. Manoun, B. Belhorma, T. Baudin, P. Berthet, R. Haumont, D. Solas, J. Phys Chem Solid. 73 (2012) 961-968.

[9] E. I. Kamitsos, J. A. Kapoutsis, G. D. Chryssikos, J. M. Hutchinson, A. J. Pappin, M. D. Ingram, J. A. Duffy, Phys. Chem. Glasses. 36 (1995) 141-49.

[10] A. M. Efimov, J. Non-Cryst. Solids. 209 (1997) 209-26.

[11] D. Laudisio, M. Catauro, A. Aronne, P. Pernice, Thermochim. Acta. 94 (1997) 173.

[12] Hui-Fen Wu, Chung-cheng Lin, Pouyan Shen, J. Non-Cryst. Solids. 209 (1997) 76. 